\title{
A PROPOSAL OF A CHEAP AND SIMPLE METHOD OF MEDICAL PERSONNEL PROTECTION FOR ENDOTRACHEAL INTUBATION OF PATIENTS WITH A SUSPECTED OR CONFIRMED COVID-19 INFECTION
}

TOMASZ GASZYŃSKI, MICHAŁ FEDORCZAK, and JAKUB PONDEL

Medical University of Lodz, Łódź, Poland

Department of Anesthesiology and Intensive Therapy

\begin{abstract}
Objectives: The COVID-19 pandemic has created additional risks to healthcare providers, especially those who perform aerosol generating procedures (AGPs) like endotracheal intubation. Endotracheal intubation is one of the procedures mostly generating aerosol and, therefore, requiring full protection of medical personnel against the infection. Material and Methods: In this paper, basing on a literature review, the recommended intubation procedure is presented together with recommendations for personal protection during intubation. Additionally, a proposal of a simple and cheap protective barrier is described against spreading aerosol outside the intubation area. The aim was to propose a simple and cheap method to increase the safety of medical personnel performing AGPs in patients infected or suspected of being infected with COVID-19, which could be easily introduced into clinical practice. Results: The presented method is the authors' own idea, based on their experience gathered from working in an operating room. Judging from their clinical experience, the presented method is effective and safe for patients. Conclusions: Endotracheal intubation is one of the most common AGPs and adequate actions must be taken in order to protect medical personnel against the infection and to prevent the spreading of aerosol around the intubation area. The proposed barrier is easy to set with disposable materials and standard equipment available in every operating room. Int J Occup Med Environ Health. 2021;34(2):301-5
\end{abstract}

Key words:

intubation, infection, personal protective equipment, airway management, COVID-19, intubation barrier

\section{INTRODUCTION}

As endotracheal intubation is one of the common aerosol generating procedures (AGPs), medical personnel should use the adequate personal protective equipment (PPE), including full PPE for AGPs and respiratory protection, preferably with an FFP3 filter, goggles, a face shield, and gloves [1]. According to the Italian recommendations, third-level PPE is the most effective [2]. The Chinese So- ciety of Anesthesiology also recommends third-level PPE and "[i]f available, a medical protective head hood or a powered air purifying respirator should be used. Goggles and glasses need to be prepared for anti-fog" [3]. The Australian recommendations compliant with the Safe Airway Society principles of airway management and endotracheal intubation specific to the COVID-19 adult patient group [4] propose that the minimum PPE should be as

Received: September 13, 2020. Accepted: January 25, 2021.

Corresponding author: Tomasz Gaszyński, Medical University of Lodz, Department of Anesthesiology and Intensive Therapy, Kopcińskiego 22, 90-153 Łódź, Poland (e-mail: tomasz.gaszynski@umed.lodz.pl). 
follows: "[i]mpervious gown, theatre hat, N95 mask, face shield and eye protection, consider double gloves."

Simulation with non-visible fluorescent compounds has revealed droplets on the medical personnel's neck, ear and shoes [5]. Guidelines for managing airways in patients with COVID-19 were proposed by the Difficult Airway Society [6]. It is prudent to use videolaryngoscopy rather than direct laryngoscopy for intubation because the former increases the distance between the healthcare worker's face and the patient's face, which may minimize the risk of contamination [7]. Videolaryngoscopy with dispensable blades is highly recommended in patients with a suspected infection $[2-4,6]$. Face mask ventilation should be avoided and pre-oxygenation should be performed using a well-fitting occlusive face mask attached to a manual ventilation device with an oxygen source for $5 \mathrm{~min}[3,4,6]$. Rapid sequence induction is the most preferable method of inducing anesthesia in COVID-19 patients [6].

Intravenous lidocaine at a dose of $\geq 1.5 \mathrm{mg} / \mathrm{kg}$ is effective in suppressing coughing during endotracheal intubation $[7,8]$. If a nasal cannula is in place, a facemask should be wellsealed over the nasal cannula. Opioids have the potential to cause coughing, which is why some providers prefer to give opioids after the accomplishment of satisfactory muscle relaxation [7]. After 45-60 s (unlike the regular rapid sequence intubation of $30 \mathrm{~s}$ ), the intubation attempt should be performed. Time extension is required to obtain a full neuromuscular blockade to avoid cough reflex during intubation. If the patient requires face mask ventilation due to low pulmonary reserves and quick desaturation, it is recommended to cover the patient's mouth and nose with 2 layers of wet gauze and ventilate the patient with a bagmask [7]. The use of supraglottic airway devices for oxygenation and ventilation can also be considered.

Each endotracheal intubation can be associated with the risk of failure, also when it comes to patients with a suspected or confirmed COVID-19 infection. Equipment for difficult intubation, such as laryngeal masks, disposable endotracheal tube stylets and a disposable fiberscope, should be prepared [7]. According to the available recommendations, awake intubation should be avoided [2,7]. In the case of patients with predicted difficult airways, the strategy and risk should be determined individually. Fiberscope assisted videolaryngoscopy can be considered after full muscle relaxation. To reduce the risk of failure and to repeat intubation attempts, the most experienced and skilled anesthesiologist should perform intubation $[9,10]$. Finally, the number of staff members involved should be cut to the minimum, and the strategy should be discussed before attempting intubation [6].

\section{METHODS}

In available publications, there are different PPE recommendations for the intubation of patients with COVID-19 [11]. In a publication based on Wuhan anesthesiologists' experience, third-level PPE is the most recommended [7,11]. Anesthesiologists should wear disposable fluid repellent coveralls, FFP2 masks (or N95 respirators), full-face shields or visors and gloves [12]. This type of protection is reasonable but has some limitations in emergency situations when airways management is required immediately. Nevertheless, in patients with a confirmed COVID-19 infection, this approach is necessary. In the publication entitled "Recommendations for endotracheal intubation of COVID-19 patients" [13] in Anaesthesia and Analgesia, a recommendation is made to wear a fit-tested N95 respirator, a face protector such as a shield, a gown, and gloves [13].

Due to the fact that not all patients can be tested for COVID-19 and given the risk that coronavirus can be transmitted by people without symptoms, all patients should be treated as potentially infected. To reduce the risk of virus transmission and operating room contamination, the newest publications recommend different strategies, including the use of protective barrier enclosures [14]. Unfortunately, this requires additional funds to buy specialized equipment. 
Brown et al. [15] and Yang et al. [16] described the management of intubation in patients infected with COVID-19 using a barrier system made of clear plastic drapes and the adaptation of a plastic barrier sheet to facilitate intubation. However, based on their experience in using similar solutions, the authors of this article found out that manipulations during airways management under plastic drapes may sometimes prove difficult, especially when intubation does not go very smoothly. Therefore, they decided to modify this barrier and to create some kind of an aerosol box which is made of clear plastic drapes and screen frames used to separate the operation area from the anesthesiologist's area (the patient's head), which are standard equipment in an operating room (Figure 1). The aerosol box facilitates manipulation on the patient's airway. To this end, the authors used disposable clear plastic foil of different manufacturers, which has to display adequate transparency, with no specification of material or a clarity meter. The adequate transparency was assessed in a subjective manner - the operator decided if, in his/her opinion, transparency was at an acceptable level.

Chen et al. [17] described a new device and technique to protect intubation operators against COVID-19. They used a modified aseptic microscopy cover. They found that it had a satisfactory effect in isolating the patient's droplets without causing hypoxemia during intubation, as shown by the fact that only the inner of this simple protective sleeve received droplets during the procedure. In the case of an urgent intubation procedure, without the opportunity to quickly prepare a protective barrier, a transparent plastic bag of an appropriate size can be used to cover the patient's head $[15,16]$. In their clinical practice, the authors use a transparent foil bag sized $1.2 \times 1 \mathrm{~m}$ with much success. Every protective method, however, can limit the manipulation over the patient's head, thus making the intubation procedure more time consuming [18]. The simple aerosol box made of anesthesia frames and foil, as presented in this article, can be a suitable option because it

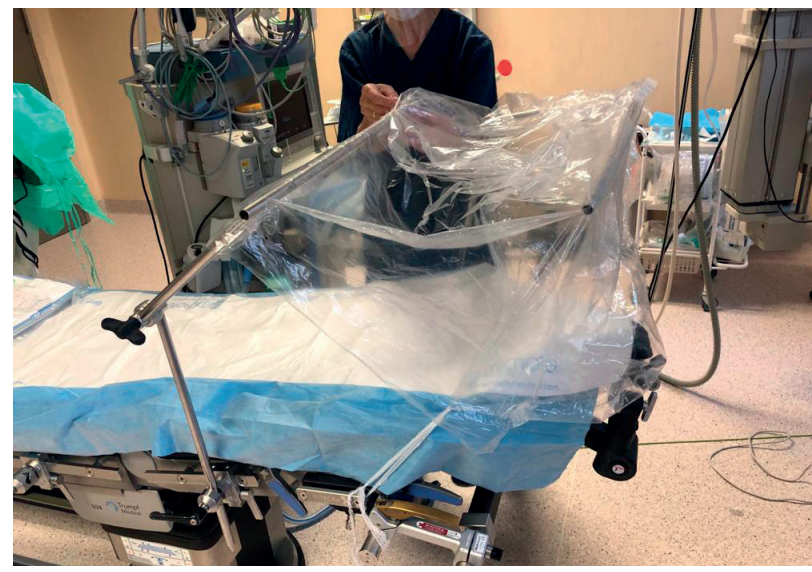

Figure 1. An aerosol box made of clear plastic drapes and screen frames used to separate the operation area from the anesthesiologist's area

makes intubation under the protective box easier, thus facilitating the management of potential difficulties during the intubation efforts.

There is no doubt about the necessity to ensure proper respiratory protection for healthcare providers in the operating room. It seems that, following the above mentioned papers, mostly filtering facepiece respirators (FFRs) and disposable respirators are used in operating rooms for protection when anesthetizing COVID-19 patients. In a paper by Sozkez and Sozkes [19] about COVID-19 and the respiratory protection for healthcare providers, the authors suggested the use of reusable elastomeric respirators, as such equipment might be less prone to leakages, can provide a better fit, and indicates a better stability compared to disposable FFRs (N95 and similar). The authors believe that adding the disposable translucent barrier proposed in this article during the intubation efforts may increase the safety of healthcare providers.

\section{RESULTS}

The authors' experience shows that improvised protective barrier enclosures can be made with easily accessible and cheap disposable materials as well as standard equipment available in all operating rooms. Anaesthesia screen 


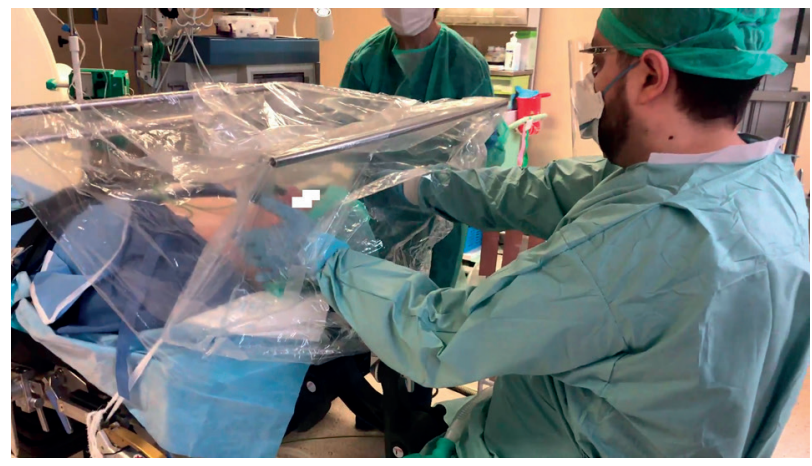

Figure 2. The aerosol box allows for manipulation in the patient's head area because of 2 small apertures for the airway operator's hands.

frames and transparent plastic foil can be used to this end. Figure 1 shows how the foil can be attached to the screen frame and how the patient's upper body can be covered. This method does not limit visibility of the videolaryngoscope screen and allows for very good access to the patient's head during intubation. Clear plastic drapes are positioned in such a way that they cover the airway manipulation area. From the anesthesiologist's side, there are 2 small apertures for the airway operator's hands (Figure 2). Attaching the operator's gown sleeves to the apertures with sticky tapes can be considered for providing an additional security seal and for preventing leakage from the apertures. The presented method is cheap, easy to prepare and, from the authors' clinical observations, capable of successfully blocking the spread of droplets and aerosols. Consent was obtained from the patient for photo publication.

\section{CONCLUSIONS}

In summary, endotracheal intubation of patients with a suspected or confirmed COVID-19 infection requires medical personnel to take the appropriate security measures and to use the adequate PPE. Using an improvised protective barrier along with third-level PPE can be considered to reduce virus transmission and operating room contamination. The proposed barrier is easy to set with disposable materials and standard equipment available in every operating room. The authors believe that the proposed barrier might also be used in other medical fields, e.g., during laryngology surgeries, including laryngoscopy with operations on entrance to the larynx in the case of which the surgery method is similar to laryngoscopy for endotracheal intubation.

\section{REFERENCES}

1. Weissman DN, de Perio MA, Radonovich LJ Jr. COVID-19 and Risks Posed to Personnel During Endotracheal Intubation. JAMA. 2020;323(20):2027-8, https://doi.org/10.1001/ jama.2020.6627.

2. Sorbello M, El-Boghdadly K, Di Giacinto I, Cataldo R, Esposito $\mathrm{C}$, Falcetta $\mathrm{S}$, et al. The Italian coronavirus disease 2019 outbreak: recommendations from clinical practice. Anaesthesia 2020;75(6):724-32, https://doi.org/10.1111/anae. 15049.

3. Zuo M, Huang Y, Ma W, Xue Z, Zhang J, Gong Y, et al. Expert Recommendations for Tracheal Intubation in Critically ill Patients with Noval Coronavirus Disease 2019. Chin Med Sci J. 2020;35(2):105-9, https://doi.org/10.24920/003724.

4. Brewster DJ, Chrimes N, Do TBT, Fraser K, Groombridge CJ, Higgs A, et al. Consensus statement: Safe Airway Society principles of airway management and tracheal intubation specific to the COVID-19 adult patient group. Med J Aust. 2020;212(10):472-81, https://doi.org/10.5694/mja2.50598.

5. Feldman O, Meir M, Shavit D, Idelman R, Shavit I. Exposure to a surrogate measure of contamination from simulated patients by emergency department personnel wearing personal protective equipment. JAMA. 2020;323(20):2091-3, https:// doi.org/10.1001/jama.2020.6633.

6. Cook TM, El-Boghdadly K, McGuire B, McNarry AF, Patel A, Higgs A. Consensus guidelines for managing the airway in patients with COVID-19: Guidelines from the Difficult Airway Society, the Association of Anaesthetists the Intensive Care Society, the Faculty of Intensive Care Medicine and the Royal College of Anaesthetists. Anaesthesia. 2020;75(6):785-99, https://doi.org/10.1111/anae.15054. 
7. Meng L, Qiu H, Wan L, Ai Y, Xue Z, Guo Q, et al. Intubation and Ventilation amid the COVID-19 Outbreak: Wuhan's Experience. Anesthesiology March 2020;132(6): 1317-32, https://doi.org/10.1097/ALN.0000000000003296.

8. Aminnejad R, Salimi A, Saeidi M. Lidocaine during intubation and extubation in patients with coronavirus disease (COVID-19). Can J Anesth. 2020;67:759, https://doi. org/10.1007/s12630-020-01627-2.

9. Yao W, Wang T, Jiang B, Gao F, Wang L, Zheng H, et al. Emergency tracheal intubation in 202 patients with COVID-19 in Wuhan, China: lessons learnt and international expert recommendations. Br J Anaesth 2020;125(1):e28-37, https://doi.org/10.1016/j.bja.2020.03.026.

10. Peng PW, Ho PL, Hota SS. Outbreak of a new coronavirus: what anaesthetists should know. Br J Anaesth. 2020;124(5): 497-501, https://doi.org/10.1016/j.bja.2020.02.008.

11. Luo M, Cao S, Wei L, Tang R, Hong S, Liu R, et al. Precautions for Intubating Patients with COVID-19. Anesthesilogy. 2020:132(6):1616-8, https://doi.org/10.1097/ALN.00000 00000003288 .

12. Wax RS, Christian MD. Practical recommendations for critical care and anesthesiology teams caring for novel coronavirus (2019-nCoV) patients. Can J Anesth. 2020;67:568-76, https://doi.org/10.1007/s12630-020-01591-X.

13. Orsen BA. Recommendations for Endotracheal Intubation of COVID-19 Patients. Anesth Analg. 2020;130(5):1109.
14. Canelli R, Connor CW, Gonzalez M, Nozari A, Ortega R. Barrier Enclosure during Endotracheal Intubation. New Eng J Med. 2020;382:1957-8, https://doi.org/10.1056/NEJMc 2007589.

15. Brown S, Patrao F, Verma S, Lean A, Flack S, Polaner D. Barrier System for Airway Management of COVID-19 Patients. Anesth Analg. 2020;131(1):e34-5, https://doi.org/10. 1213/ANE.0000000000004876.

16. Yang YL, Huang CH, Luk HN, Tsai PB. Adaptation to the Plastic Barrier Sheet to Facilitate Intubation During the COVID-19 Pandemic. Anesth Analg. 2020;131(2):e97-9, https://doi.org/10.1213/ANE.0000000000004923.

17. Chen C, Shen N, Li X, Zhang Q, Hei Z. New device and technique to protect intubation operators against COVID-19. Intensive Care Med. 2020;46,1627-9, https://doi.org/10.1007/ s00134-020-06072-9.

18. Begley JL, Lavery KE, Nickson CP, Brewster DJ. The aerosol box for intubation in coronavirus disease 2019 patients: an in-situ simulation crossover study. Anaesthesia. 2020;75:1014-21.

19. Sozkes S, Sozkes S. COVID-19 and respiratory protection for healthcare providers. Int J Occup Med Environ Health. 2021;34(2):307-18, https://doi.org/10.13075/ijomeh. 1896.01666.

This work is available in Open Access model and licensed under a Creative Commons Attribution-NonCommercial 3.0 Poland License - http://creativecommons.org/ licenses/by-nc/3.0/pl/deed.en. 